\title{
VISIONES ÉTICO-ESTÉTICAS SOBRE LA FEMINIDAD. CONCEPCIONES JUVENILES Y SOCIO-LEGISLATIVAS EN LA CONSTRUCCIÓN DE LA IMAGEN FÍSICA DE LA MUJER OCCIDENTAL ${ }^{1}$
}

\author{
Cecilia Serrano-Martínez ${ }^{2}$
}

\begin{abstract}
Visiones ético-estéticas sobre la feminidad. Concepciones juveniles y socio-legislativas en la construcción de la imagen física de la mujer occidental.

Resumen: Las sociedades occidentales asimilan un prototipo femenino en cuya creación participan diversos factores. La sociedad adquiere dicho prototipo y crea un discurso generalizado acerca del ideal de mujer. El presente artículo plasma la visión y posición de la mujer en el espacio público y como su apariencia juega una pieza clave en su identidad. Para conocer la percepción corporal es preciso analizar la parte instituida, tomando como referencia el Observatorio de la Imagen de las Mujeres. También se analiza la parte instituyente, desde los discursos juveniles, para conocer su aceptación o rechazo hacia estas conductas de belleza creadas.Palabras clave: Ciudadanía, mujer, espacio público, imagen, imaginario.
\end{abstract}

Ethical-Aesthetic Visions of Femininity. Youth and Socio-Legislative Perceptions in the Construction of the Physical Image of Western Women.

Abstract: Western societies assimilate a female prototype whose creation involves several factors. The society adopts this prototype and creates a discourse about the widespread ideal woman. This paper aims to capture the vision and position of woman in the public space and how her appearance plays a central role in her identity. In order to get a better understanding of body perception, it is necessary to analyze the instituted part, through the "Observatorio de la Imagen de las Mujeres". Likewise, the instituting part is analyzed, in order to know how young people are supporters or detractors of this behaviour of established beauty.

Key words: Citizenship, women, public space, image, imaginary.

\section{Introducción y justificación del trabajo de investigación}

En la actualidad, al hablar de género y diferencias entre hombres y mujeres parece que existe intrínsecamente un sistema construido socialmente y conformado por unas

\footnotetext{
${ }^{1}$ Fecha de recepción: 26/05/2014.

Fecha de aceptación: 16/06/2014.

${ }^{2}$ Miembro del Personal Investigador en Formación, Departamento de Psicología y Sociología, Universidad de Zaragoza, España; $₫$ cserran@unizar.es.
} 
relaciones de poder y de subordinación, que crean diferentes tareas y roles sexuales en los que la mujer se ha visto mayormente perjudicada. La inquietud de realizar este estudio nace a raíz de querer responder dos hipótesis de partida. En primer lugar, la posible influencia directa o indirecta de los mensajes de los medios de comunicación, contenidos legislativos, etc., en cuanto a la feminidad que debe poseer una mujer y que afecta a las jóvenes de la sociedad actual. En segundo lugar, con la cuestión de sí todavía se le exigen mayores cuidados a los cuerpos femeninos que a los masculinos en estas demandas. Esta segunda hipótesis considera que la intensidad de demandas hacía las cualidades femeninas son mayores y que se continúan manteniendo en el imaginario ideal de la población juvenil.

A lo largo de este trabajo y reflexión, confrontamos lo instituido con lo instituyente. Aquellos elementos considerados como instituidos se alcanzarán mediante un estudio de la legislación relacionada con la mujer y con el cuidado, y mediante documentos extraídos del Observatorio de la Imagen de las Mujeres. En ambos casos, buscamos contrastar el ideal de mujer y conocer si lo defienden o critican y que aportaciones realizan al respecto. Por otro lado, es necesario analizar lo instituyente para valorar si lo instituido coincide con la realidad y la opinión de las personas. Por lo que mostramos las visiones en primera persona de diferentes mujeres y hombres contemporáneos entre 18 a 24 años de edad.

Es un factor de vital importancia para la sociedad española conocer los discursos juveniles en la creación de una identidad social. Siguiendo a Jesús Ibáñez (1985: 229), "el lenguaje hablado es la única posibilidad de manifestar el lenguaje (...) y funciona como equivalente general de valor de todas las prácticas significantes". Por ello, conocer el hablar grupal de estos jóvenes es el objeto principal de esta investigación, ya que son partícipes de los continuos cambios sociales, que generan discursos variados sobre el ser y el deber ser. A estas realidades hay que dotarles de un valor y un significado, mediante la percepción de aquellas personas jóvenes que cumplen la función de mantenimiento o de cambio en las sociedades actuales.

La idea de este estudio no es centrar la mirada en los diversos tipos de construcciones femeninas, ya que diversas autoras ya lo han trabajado (Butler, Despentes, 
Haraway, Preciado), pero resulta interesante valorar la continuidad de estas realidades sociales desde las prácticas y experiencias de los jóvenes. Con los resultados de esta investigación pretendemos aportar otros tipos de percepciones en el ideal de la mujer occidental actual.

\subsection{De lo instituido y lo instituyente}

Las relaciones entre lo instituido y lo instituyente pasa por la consideración de la resistencia instituyente, la cual incluye tres niveles de reflexividad (Bergua 2007: 199). Se tratan de niveles que estando presentes, se descubren conforme se van investigando. Siguiendo las aportaciones de José Ángel Bergua (2007: 200-201), el primer nivel es en el que se proyecta la realidad y se entiende en términos de ser o no ser, que se refiere a lo instituido y a lo instituyente. En el segundo nivel la proyección se centra en la observación de la realidad, por lo que se trata de una introspección subjetiva, ya que es la visión observada. La tercera y última reflexión es sobre la construcción de la realidad, la cual se presenta como constructivista y se incluyen los dos niveles anteriores, en tanto a la observación y realidad, los cuales "forman parte de un curso de acción o de vida". E1 pensamiento no es independiente de lo instituido y de lo instituyente, por lo que en el camino por alcanzar estos niveles de reflexividad, serán ambas fuerzas las que se incluyen en el pensamiento y en la acción.

Introducir los conceptos de lo instituido y lo instituyente en el ideal final de mujer pasa por la proyección de este en el espacio público. Son diversos autores los que se han centrado en dotar de un significado al espacio público. Según Tamar Pitch (2003: 279), que toma la fórmula de Iris Young (1996), señala que existen tres modos de entender el espacio público. En primer lugar, señala que se trata de una esfera de "legítima intervención colectiva", en la que tomará parte el gobierno y el estado. En segundo lograr, "una esfera de interacción y comunicación intersubjetiva" en la que se pone de manifiesto lo accesible al resto de la sociedad, a la vez que se dota de una participación ciudadana. 
En tercer lugar, se trata de una "esfera de lo político" que otorga la parte funcional al sistema.

En el espacio público se reflejan los conceptos finales del ser, a la vez que se realiza una presentación de uno/a mismo/a en la sociedad. En este reconocimiento físico y social, la legislación ocupa la posición de definir el orden social de lo que quiere construir, que se trata del peso instituido desde la ley. Del mismo modo, los medios de comunicación y la publicidad, plasman esa idea de belleza, cuidado, estética, lo que lleva a crear, de nuevo, una posición instituida del ideal femenino.

Para entender cómo es el orden instituido en relación al cuerpo femenino, hay que conocer la parte instituyente, es decir, la realidad en estas prácticas finales de la mano de las mujeres y de hombres que se relacionan con ellas. El hacer que estas realidades impuestas desde lo instituido sean parte de lo instituyente, puede terminar en el plano del imaginario y crear "formas culturales híbridas que estarán, a la vez dentro y fuera de la Sociedad instituida" (Bergua 2007: 85). Un modo de crear estas formas culturales es por medio de la opinión pública, la cual tiene que ver con lo que Rodrigo Fidel Rodríguez y Domingo Fernández (2008: 13) denominan un "sustrato común de pensamiento y acción”. Entienden que se desarrolla con la existencia de una ciudadanía que la crea, a la vez que posibilita la existencia de la opinión pública. Por lo tanto, es en torno a estas dos realidades donde hay que indagar sobre el resultado final de lo instituido, sobre las personas que realizan la acción, aceptación o rechazo de lo imaginado y/o creado.

Para abordar lo público y crear pautas instituidas, es necesario alcanzar un adecuado conocimiento del efecto instituyente. Por lo tanto, no hay que obviar las pautas legislativas y de control de la imagen, puesto que, y siguiendo a Pablo Cottet (2006: 187): "para hacerse de un interior institucional hubo de conquistar un exterior, hubo una primacía del momento instituyente para acumular lo instituido que posibilitara luego su despliegue, un despliegue instituyente guiado por lo instituido". Es en la conquista de este exterior dónde sitúa la investigación: desde las realidades legislativas y publicitarias actuales hasta el discurso juvenil sobre estas influencias. 
1.2. Publicidad y legislación: de lo instituido y del deber ser

El ordenamiento jurídico español da respuesta a la publicidad por medio de la Ley 34/1998, de 11 de noviembre de 1988, general de publicidad. En el artículo 3 se explican los casos de publicidad ilícita, véase: aquella que atente contra la dignidad de la persona o vulnere los valores y derechos que se reconocen en la Constitución, sobre todo aquellos referidos a la infancia, la juventud y la mujer.

Comprender la publicidad lleva intrínseco incluir a los sujetos partícipes de ésta, que son los llamados sujetos publicitarios (Acosta Estévez 1990: 31). Los medios de comunicación, entre otras funciones, son transmisores de ideologías, por lo que, "es preciso considerar cómo el sistema de medios de masas tiene un importante papel como reproductor y elaborador de los mitos entorno al ser humano", y la publicidad sería el elemento demonizado de los medios de masas (Rodríguez y Fernández, et al. 20008: 120). Según Erving Goffman (1991: 143) en publicidad se presentan personajes idealizados, a través de medios ideales para conseguir unos fines que están unidos por relaciones del mismo modo ideales. Estos métodos son utilizados por los medios publicitarios, gobiernos y organizaciones de fin no lucrativo, para hacer llegar sus mensajes a través de prensa, carteles, Internet, etc.

Una de las funciones de la publicidad es la de transmitir contenidos con objeto de adquisición final por parte del consumidor o de la modificación de su actitud ante temática. Según Miguel Roiz (2002: 70) la intención principal de la publicidad es la de "influir en las actitudes y comportamientos sociopolíticos de los ciudadanos". Considera que los contenidos mostrados responden a una selección previa de temas estereotipados formados por diversos modos de actitud. De nuevo, el papel del ciudadano pasa a un segundo plano, ocupando una función de objeto y no de sujeto.

El sujeto termina por ser consumidor de los valores femeninos de belleza, juventud y delgadez, exaltados por los medios publicitarios, ya que terminan por convertirse en "verdades absolutas e incuestionables" (Santiso 2001: 49). Estos ideales de belleza llevan 
en paralelo la devaluación de la vejez, la cual no aparece reflejada en la publicidad al mismo nivel que la imagen de una mujer joven. En relación al consumismo, publicidad y mujer, Raquel Santiso (2001: 52) considera que un recurso publicitario para aumentar el consumo femenino de productos es mediante el convencimiento de esa belleza a alcanzar, lo que conlleva intrínseco el recurso comercial de bajar la autoestima de las mujeres en la percepción de su propio cuerpo.

En paralelo a este "ideal de mujer", son variadas las formas legislativas que regulan aspectos relacionados con los medios que garantizarán un perfeccionamiento del cuerpo. En sus inicios, la regulación de los cosméticos se realizó con el Decreto 3339/1968, de 26 de diciembre, que dicta normas sobre registro, elaboración, publicidad y venta de cosméticos. En el artículo 29 se determina que "la publicidad de los cosméticos será leal y no inducirá a error”. El Real Decreto 349/1988, de 15 de abril, ratificó la reglamentación técnico-sanitaria de productos cosméticos e incluye la lista de los productos considerados como cosméticos. Varios de estos productos se dirigen a frenar los síntomas de vejez (antiarrugas) y a mantener rasgos físicos relacionados con la juventud y la belleza (maquillaje, bronceado, etc.). Años más tarde, se realizaron modificaciones mediante el Real Decreto 475/1995 de 5 de abril. A parte de este también tenemos el Real Decreto 1599/1997, de 17 de octubre, sobre productos cosméticos.

Las leyes son creadoras de un marco normativo, que a la vez construye una imagen de la mujer, de los varones y de la relación entre ambos. El significado de legislativo hay que comprenderlo en términos contextuales, ya que se modifican con el paso del tiempo y en función de las demandas que acontecen en cada periodo histórico. En el caso de la legislación relacionada con las mujeres, Pitch (2003: 261) considera que "las vidas concretas de las mujeres no se dejan encerrar ni comprender, en las rígidas rejas del derecho privado o del derecho público". Por ello, abarcar los significados legislativos y normativos pasará por la consideración individual de cada experiencia situada en un determinado momento socio-económico y político.

Evitar recrear las imágenes contenidas en los recursos publicitarios y realizar legislaciones objetivas pasaría por la construcción de modelos fuertes, que según 
Clemente de Miguel (2004: 8) implica una recuperación de la dignidad y un cambio en el mensaje hacía la noción de que todo no vale. Para alcanzar este fin, previamente "se necesita sobreponer los valores del ser sobre los del parecer". El discurso social se dirigiría hacía un cambio en la presentación en el espacio público, el cual no pasaría únicamente por la imagen corpórea ni por la realización de una publicidad basada en una apariencia física de belleza sobre la propia esencia del ser individual.

1.3. Espacios públicos: escenarios del rol social

En el marco del espacio público convergen los lenguajes y modos de comunicar los mensajes del "ideal de mujer". El cuerpo, además de ser materia lingüística, influye constantemente en el mensaje (Butler 2002: 110), por lo que el imaginario que se muestre sobre este ideal de lo femenino será el que anime a ser reproducido por las mujeres. Por ello, los espacios públicos pasan a ser los escenarios de una realidad visualizada en diferentes ámbitos, tales a, publicidad, medios de comunicación, etc. Lo cual llevaría a pretender identificar el cuerpo femenino con el ideal del yo, que se manifestaría con la creación y transformación del cuerpo (Lacan 1977: 4). Hay una serie de dificultades a las que se está enfrentando la sociedad occidental, como estar inserta en una cultura donde la idea de mente-cuerpo están separadas, lo cual genera dificultades para llegar a un entendimiento en la forma de entender y educar al cuerpo. La posición del cuerpo es otro de los elementos clave en este análisis, ya que se ha convertido en una forma de regulación de la sociedad.

1.4. Enfoques y visiones del supuesto ideal femenino

Es la tradición dualista reflejada en la sociedad la que transmite cómo se entiende ser mujer o ser hombre en las sociedades actuales. Con más frecuencia se realizan lecturas 
más negativas de la imagen corporal, que impiden que la mujer se vea tal y cómo es. Los últimos estudios sobre sexualidad junto a otros más antiguos recuperados, teorías Postestructuralistas y la Teoría Queer, han contribuido de manera determinante a la redefinición de los conceptos para romper con ese pensamiento dualista referido a términos como: hombre/mujer, masculino/femenino, sexo/género, que aparecen de esa oposición binaria de corte estructuralista entre naturaleza y cultura. Una manera de terminar con esta posición binaria de los términos según García $(1994: 174,175)$ es mediante la "necesidad de una diferencia universal o de una femineidad universal". Señala que en la ruptura de estas dicotomías, van accediendo al discurso público diferentes experiencias, caracterizadas por la diversidad de culturas, que surgen de colectivos de mujeres que no son blancas ni euroamericanas. En la lucha contra el género también aparecen cada vez más mujeres concretas o grupos que se presentan como nuevas féminas creando "otras imágenes y otros símbolos de lo femenino que las instituciones y, hasta la moda, han de tener en cuenta" (Amorós 2000: 283). Entre ellas aparece Donna Haraway (1991: 344) la cual señala que el cuerpo en el discurso de la biología se posiciona como ser atractivo, pero le dota de movimiento propio, ya que el cuerpo "es un agente, no un recurso". Presenta a la mujer como la hembra biológica, a la cual no le quedan propiedades pasivas, y “es estructurante y activa en todos aspectos".

En el debate del cuerpo se incluye la posición de la supuesta femineidad, del comentado ideal de mujer. Virginie Despentes (2007: 106) tras años de investigación llega a la conclusión de que la femineidad es una hipocresía, a pesar de que se le dote de adjetivos de seducción, ya que al fin y al cabo, lo que implica es la asunción de unos comportamientos propios de un ser inferior. La posición del ideal femenino hacia el hombre exige que la mujer elimine de su comportamiento todos signos de potencia. El ideal de virilidad masculina no ha cambiado en los últimos cuarenta años, lo cual posiciona en el lado opuesto las conductas consideradas femeninas, que terminan por ser las cosas más pequeñas. En el lado de lo supuestamente viril, Despentes (2007: 107) enumera las grandes cosas asociadas como propias de lo masculino: "ganar mucha pasta: viril, andar como te dé la gana: viril, (...) no arreglarse por las mañanas: viril, llevar ropa 
práctica: viril. Todas las cosas divertidas son viriles, todo lo que hace que ganes terreno es viril".

Los jóvenes son los protagonistas en el cambio o el mantenimiento de este ideal de la posición femenina como presentación externa en su cuerpo y cuidado. En particular, a las mujeres más jóvenes se les responsabiliza de sus pautas de cuidado e imagen, ya que posteriormente dependerá de ellas. Simone de Beauvoir (1976: 98) reflejó que las mujeres jóvenes consideraban como necesario exigirse a sí mismas y que presentaban una actitud de derrotismo hacía su futuro. Conocer si ha existido un cambio en las pautas juveniles y en la posición y reconocimiento del papel que los jóvenes ocupan en la sociedad, como creadores de su presente y transmisores de ideales a futuro, es una de las inquietudes de esta investigación. Por lo que, procedemos a presentar la metodología utilizada para alcanzar un conocimiento del estado actual de los temas comentados, y una posterior reflexión con las aportaciones del discurso juvenil.

\section{Metodología}

Para realizar un correcto análisis de la información es de vital importancia establecer una adecuada metodología, ya que "las formas en que los miembros investigan constituyen rasgos de los escenarios que analizan" (Garfinkel 2006: 18). Hemos utilizado los grupos de discusión como metodología principal de investigación, por la consideración de que son las mejores técnicas cualitativas para alcanzar una opinión pública contrastada en conjunto y para alcanzar consensos sobre los temas que se desarrollan. Los discursos extraídos de los grupos constituyen la materia prima para el análisis, el cual pretende crear un informe que "servirá de contexto lingüístico para el uso social de sus resultados" (Ibáñez 1986: 135). Pretendemos crear un marco de reflexión sobre el objeto de estudio y para crear un uso social basado en posibles alternativas a las demandas que surjan a través de los discursos. Según Ibáñez (1985: 231), en el grupo de discusión se pone en juego el contexto, el proceso de producción y el producto. El grupo 
refleja la sociedad global por medio de la forma-grupo que representa al macro-conjunto de la sociedad, en la que realizan producción referida a la discusión y un producto final en cuanto el discurso que de estas interacciones se obtiene. El discurso del grupo refleja la opinión pública y captura el consenso de las realidades contrastadas en el mismo. Del mismo modo, hemos analizado material complementario legislativo relacionado con la regulación de la publicidad, medidas contra la violencia de género y otras medidas que siguen el discurso paralelo del cuidado y de la imagen. Para centrar el análisis de la publicidad, hemos estudiado los últimos Informes publicados del Observatorio de la Imagen de las Mujeres, correspondientes a los años 2000 a 2008, en particular centrando el análisis comparativo en el último año, junto a otros recursos dirigidos a la defensa, propuesta o cambio en los conceptos equívocos acerca de la difusión de la imagen femenina. En definitiva, la investigación versará sobre dos ejes principales, relacionados con la parte instituida y la parte instituyente del objeto de la investigación:

1. Instituido: Para centrar el análisis de la publicidad, hemos analizado los informes del Observatorio de la Imagen de las Mujeres, correspondientes a los años 2000 a 2008, en particular centrando el análisis comparativo en el último año, junto a otros recursos dirigidos a la defensa, propuesta o cambio en los conceptos equívocos acerca de la difusión de la imagen femenina. Hemos apoyado el análisis con legislación con un estudio de las prácticas legislativas relacionadas con la mujer, decretos y leyes realizadas en torno al cuidado del cuerpo, etc. También hemos analizado material complementario legislativo relacionado con la regulación de la publicidad, medidas contra la violencia de género y otras medidas que siguen el discurso paralelo del cuidado y de la imagen.

2. Instituyente: La metodología se realizará por medio de dos grupos de discusión. En el grupo de discusión se pone en juego el contexto, el proceso de producción y el producto (Ibáñez 1985: 231). Tal y como señala Ibáñez, el grupo refleja la sociedad global por medio de la forma-grupo que representa al macro-conjunto de la sociedad, en la que realizan producción referida a la discusión y un producto final en cuanto el discurso que de estas interacciones se obtiene. El discurso del grupo refleja la opinión pública y captura el consenso de las realidades contrastadas en el mismo. Siguiendo estas ideas, y para tener 
diferentes perspectivas del objeto de estudio, hemos realizado dos grupos de discusión diferenciados por sexos, que tienen las características siguientes:

- Grupo de Discusión 1 (en adelante GD1): Formado por ocho mujeres de entre 18 a 24 años de edad, con un nivel de estudios medio-alto, se encuentran diferenciadas por su situación personal (tener o no tener hermanas, ser de complexión fuerte o ser delgada, etc.) y por sus características o experiencias cercanas en torno a la imagen y el cuidado (conocer el mundo de la moda o no preocuparse por el mismo, fabricar sus propias prendas, etc.)

- Grupo de Discusión 2 (en adelante GD2): Compuesto por seis hombres de entre 18 a 24 años de edad, con un nivel de estudios medio-alto, y se encuentran diferenciados por su relación con las mujeres (tener o no tener novia, hermanas, etc.) y por su situación académico-profesional (trabajar con mujeres, trabajar en publicidad, etc.)

La idea de utilizar este recurso empírico es obtener un discurso por sexos y un consenso del conjunto de los jóvenes entrevistados, sobre las opiniones y vivencias acerca de la imagen de la mujer en el espacio público. Con esta metodología se obtiene una perspectiva juvenil acerca de lo anterior, así como un conocimiento de las posibles alternativas para mejorar o cambiar las situaciones que observan. Se ha buscado que respondan a cuestiones, tales como: percepción acerca de la condición de ser mujer y demandas sociales, imagen social femenina y modo de configurarla previamente, etc.

Las ideas centrales que marcan el desarrollo del grupo realizado tienen que ver con la imagen de la mujer en el espacio público, perfil/rol que desean dar y que la sociedad les demanda, influencia que tienen otras mujeres, familia, medios de comunicación y publicidad, en la construcción de su propia imagen social. También responderán a la cuestión de si se le exige más a la mujer que al hombre en el cuidado del cuerpo. De las ideas extraídas, se buscarán reflexiones acerca de un supuesto "ideal de mujer" presente en las sociedades occidentales y de la influencia que puede ejercer en estos jóvenes contemporáneos entre 18 y 24 años. 
2.1. Lo instituido: Observatorio de la Imagen de las Mujeres y legislación.

En el año 1994 el Instituto de la Mujer crea el Observatorio de la Imagen de las Mujeres (OIM), medio por el cual se hacen efectivas las denuncias referidas a aquellos contenidos publicitarios provenientes de los Medios de Comunicación de Masas, que vulneren la dignidad de las mujeres, presenten estereotipos, etc. En abril del 2007, el Instituto de la Mujer crea la Comisión Asesora de la Imagen de las Mujeres en los Medios de Comunicación y la Publicidad; donde se incluyen a las asociaciones del sector publicitario, consumidores, instituciones públicas y medios de comunicación.

Este Observatorio es el medio para canalizar las quejas que, los diferentes organismos y/o ciudadanos, les realizan a propósito de aquellos anuncios y medios comunicativos que muestren contenidos ilícitos. Una vez que se han captado las quejas, se encarga de dirigirse a las empresas que anuncian ese determinado producto, con el objetivo de que cesen sus mensajes o rectifiquen los errores inmersos en el spot, programa televisivo, Internet, etc. Además, se encarga de difundir la información obtenida para seguir creando un rechazo social en el tratamiento discriminatorio mediático.

Según los datos de los de Informes 2000-08 del OIM, la evolución de quejas totales desde el año 2000 al 2001 fue ascendente, de 339 a 710 quejas. Entre los años 2002 y 2006 ha mantenido sus cifras entorno a una media de 350-550 quejas al año. En 2008 disminuyó el número de quejas en relación al año 2007 con un 317 frente a las 1.176. El elevado número de quejas del año 2007 fue motivado porque 747 de las denuncias se realizaron a la misma campaña publicitaria en prensa.

En cuanto al número de campañas denunciadas, cabe destacar el considerable aumento que se dio entre el año 2000 al 2001, pasando de 157 a 211, respectivamente. Después de estos años, las cifras se mantuvieron prácticamente estables, con una diferencia máxima de 40 campañas denunciadas en el baremo de 2001 a 2006, el cual oscila entre 171 y 211 quejas al año. A partir del año 2007 ha disminuido el volumen de 
campañas denunciadas, lo que significa que las quejas se reiteran entorno a varios casos concretos de spots publicitarios. En 2008 el porcentaje mayoritario de quejas se centra en televisión con un $42 \%$ frente al $12,5 \%$ del año 2007. Las quejas a otros soportes informáticos han aumentado en más de 10 puntos, de un 4'9\% a un 15,4\% en 2008.

Tomando como referencia el informe publicado en el año 2008 en el OIM, cabe señalar unos datos de interés. En primer lugar, ha habido un total de 317 quejas, lo que supone un descenso del 73\% en relación al año 2007 y un descenso del 9\% en el número de campañas denunciadas. Del porcentaje de personas que denuncian un 14,8\% de las denuncias han sido realizadas por hombres, frente al 35,6\% de las que presentaron en el año 2007. Las Comunidades Autónomas que más quejas presentaron en 2008 fueron: Madrid con un $40,5 \%$, Valencia con un $8,2 \%$ y Cataluña con un 7,5\%. El perfil más reiterado de denunciante es el de mujer con una edad comprendida entre los 26 y 35 años, soltera, licenciada, con trabajo y cuyo hábitat es el urbano.

En relación al último año, los motivos de las denuncias mayoritarias son, en primer lugar, un $21,1 \%$ por atentar contra la dignidad de la mujer, frente al $68 \%$ presentado en 2007. En segundo lugar, 18,6\% presentaban estereotipos domésticos, y en tercer lugar, $14,2 \%$ por tratar a las mujeres como un objeto sexual. Los mensajes de violencia aumentan en los criterios de denuncia de un 5,1\% a un 10,4\%. El resto de los motivos son: cuerpo femenino como reclamo, discriminación, confrontación de sexos, belleza como valor de éxito y lenguaje sexista.

Las principales conclusiones del último informe del año 2008 son que las apariciones por sexo son equitativas, pero en el papel de la mujer se mantienen estereotipos de la maternidad y en el hombre estereotipos profesionales. Se ha introducido la figura femenina en el trabajo remunerado, pero manteniendo la vinculación al ámbito doméstico. Se pretende crear una educación en las féminas basada en el romanticismo y los intentos de transgredir los estereotipos terminan por ser "forzados y poco naturales". Los jóvenes aparecen compartiendo actividades de ocio, logrando situar la amistad como el mejor contexto para de la igualdad. 
El espacio público queda reservado para los hombres, los cuales informan, toman decisiones y utilizan la alta tecnología. En general, las mujeres mantienen la posición emotiva, de cuidado, cariño y estética. Los cuerpos femeninos desnudos simbolizan una fusión con la naturaleza. Se utiliza el envejecimiento y el peso como problemas patológicos que hay que solucionar por medio del cuidado personal. El Observatorio recibe cada vez más quejas de otros contenidos como Internet o programas de televisión, lo que pone de relieve que la transmisión de estereotipos se está generalizando.

En cuanto a la procedencia de las quejas 298 fueron de particulares y 13 de entidades. Por denuncias como estas, el Instituto de la Mujer ha contactado con 15 empresas con objeto de que modificasen su contenido o retirasen esos anuncios ilícitos, y con 12 empresas para aconsejarles de los posibles cambios que deberían dar para adecuar el mensaje publicitario.

En el orden instituido de la legislación las pautas normativas están marcadas con el carácter de trasfondo de cada momento y circunstancia en el que se crean. La Ley de Publicidad, la cual tiene más de veinte años de antigüedad, no se ha modificado en sus bases y mantiene la lucha contra la publicidad ilícita como sello de garantía. Para entender la inclusión de estas leyes publicitarias en España hay que tener una visión más amplia y con una referencia en el contexto europeo; ya que de no haber tenido que adaptar sus normativas al Consejo de las Comunidades Europeas de 1984, quizás la normativa española tendría otros matices menos capaces de dar respuesta a las situaciones denigrantes, en cuanto a ética publicitaria.

En cuanto a las leyes publicitarias, hemos observado que no se adaptan al sistema de valores actual, puesto que aquello que consideran como publicidad ilícita abre un discurso un tanto difuso, ya que el sistema de creencias y cultural actual es tan amplio que las leyes no abarcan con sus contenidos todos los significados posibles. La publicidad ilícita es aquella que atenta contra la dignidad de la persona y vulnera los derechos constitucionales referidos a infancia, juventud y mujer. El que los valores sean diversos se denota en las denuncias realizadas al Observatorio de la Imagen de las Mujeres, las cuales varían en los diferentes años; pasando de darle mayor importancia, a principios del 
siglo XXI, a los estereotipos que representan a la mujer en un papel subordinado o como objeto de valor meramente estético, a ser más denunciadas aquellas imágenes que atentan contra la dignidad de la mujer o la muestran bajo estereotipos domésticos. Estos cambios en las percepciones ciudadanas a lo largo de pequeñas franjas anuales, muestra que el orden instituido legislativo no se desarrolla a la vez que las demandas instituyentes del colectivo poblacional.

En el plano de la conformación de mecanismos legales favorecedores para el consumidor y del usuario, aparecen de nuevo ideologías instituidas por las que se anteponen funciones alejadas de las demandas instituyentes reales, tales a la escucha ciudadana o a la correcta y clara información. En vez de adaptarse a estas inquietudes, el Comité Asesor de Cosmetología tiene la función principal de consulta y asesoramiento técnico, el cual dirige los esfuerzos hacía el mercado de consumo. Del mismo modo, la Asociación de Autocontrol de la Publicidad dispone como función principal el que la publicidad sea un instrumento útil para la economía. Estas acciones se contrarrestan con el derecho de la Ley de Consumidores y Usuarios en relación a la correcta información sobre productos y servicios, educación y divulgación.

2.2. Lo instituyente: los discursos juveniles

En el apartado dedicado al análisis instituyente de la investigación hemos analizado el consenso extraído en los discursos juveniles, por medio de los grupos de discusión.

\subsubsection{Imaginarios masculinos e ideales femeninos}

La conciencia social está teniendo una incidencia directa en las ideas que las mujeres adquieren sobre ellas mismas. Les afecta en el mantenimiento de los prototipos 
que se muestran como válidos o socialmente aceptados, tales a tener la piel morena y estar delgada. El ideal también depende de las modas, que cambian a lo largo del tiempo: "Antes estaba de moda una mujer más gordita o más pálida, y ahora se ve mejor tener buen tipo y estar morena" (GD1).

Estas modas transforman el ideal de mujer y hacen que se desee alcanzar unas bases para alcanzarla. El peligro de la elevada exigencia es el de desvalorizarse cuando no observan un nivel mínimo en su apariencia física. Estos comportamientos se suelen dar desde edades tempranas, siendo el colegio un espacio de análisis del otro en el que se comienza a infravalorar a niños/as gordos/as o con alguna característica física considerada como menos positiva frente a otras. A parte de estos requerimientos entre las féminas, que llevan consigo un espíritu de competitividad, existen unos cánones establecidos según los cuales aparece un mensaje implícito relacionado con una serie de objetivos que se han de cumplir para alcanzar un sentimiento de bienestar dentro del espacio público que lo demanda: "Parece que tengas que sentirte bien contigo misma para estar a gusto, pero porque te tienes que arreglar, cuidarte las pestañas, pintarte los morros, y, ¿Por qué tienes que hacer eso para sentirte bien?" (GD1).

En esta afirmación se plantea el hecho de que socialmente se le está dando una valoración excesiva al físico, que interrelaciona el sentimiento de bienestar con la apariencia pública. El marco del espacio público demanda dos cosas diferentes a la mujer, por un lado, que este en casa y cuide de los hijos, y por otro, que se cuide físicamente y que su imagen aparezca perfecta para los demás. Los ideales de belleza femeninos han cambiado en el transcurso del tiempo, y el prototipo actual se aproxima a la idea de estar morena, tener un cuerpo delgado. Alcanzar estos ideales crea una obligación y dependencia, que se traduce en un estrés por lograr unos roles de perfección. La influencia que reciben de la concepción externa tiene mayor importancia que la propia, con el consiguiente riesgo de realizar conductas perjudiciales para su salud por alcanzar la aprobación ajena.

La belleza externa termina por posicionarse sobre la interna como garante de éxito personal. Se trata de una dependencia que genera mayor inseguridad, por el componente materialista que resulta de las opiniones. Aquellas féminas que no se preocupan por seguir 
las líneas de cuidados e ideales terminan por ser indiferentes, ya que no aparecen en el discurso colectivo que admite un único modelo de mujer a imitar, por lo que podríamos hablar de una femineidad invisible. Dicen que son las mujeres que "no tienen nombre, ni tienen voz, ni nada”, pero que a pesar de no querer seguir el canon establecido no se las critica porque cada vez la sociedad es más diversa y no existe un rechazo a lo que es menos habitual o diferente a lo común.

2.2.2. Imagen social como deseo de auto-reconocimiento y nuevo ideal de hombre

Existe una especie de comparación entre las féminas en relación a su imagen y a su cuerpo, y modifican su físico con la llegada a la universidad para sentirse aceptadas. Dicen que la gente busca la aprobación y ocupar un lugar frente a los demás, aunque existe el riesgo de que estos cambios afecten a su forma de ser. El problema en querer alcanzar estas pautas de cuidado para el auto-reconocimiento, surge cuando no se realizan por el propio bienestar y se hace por imitación. El modelo escogido como prototipo marca el comportamiento de muchas mujeres que adquieren estas pautas como criterio de valoración social: "Si todos fuéramos sin arreglar pues valoraríamos otras cosas, pero ahora se valora eso" (GD1).

La necesidad de buscar el reconocimiento ajeno surge por una falta de valoración personal, ya que terminan manteniendo estas prácticas para escuchar el resultado desde el reflejo externo. Las modas cambian más deprisa para las mujeres que para los hombres, ya que son más dinámicas y el mercado de elección es más amplio. El que un hombre padezca en menor grado la presión de la moda, viene implícito por un menor volumen de exigencia personal y social, y por un mercado de consumo masculino en torno a la belleza que está menos desarrollado. La mujer pasa a situarse en un plano de la sensualidad, en el que su forma de vestir y de personificarse en público determina el índice que explota de su capacidad de atracción hacía el colectivo masculino. 
Visualizan que estas exigencias han pasado a ser una norma silenciosa, en la que se establece la imagen que las mujeres han de llevar. A pesar de que al hombre no le terminan por afectar del mismo modo, comienzan a ser más frecuentes los "hombres metrosexuales", caracterizados por depilarse, consumir productos cosméticos, etc. Este nuevo rol masculino se presenta en los medios de comunicación como prototipo a alcanzar. El modelo de hombre que se quiere instaurar surge a consecuencia del mantenimiento de una moda creadora de las características óptimas en la belleza masculina, que se crean a través del lenguaje, la cultura y la imagen.

El que las mujeres quieran mejorar su autoestima por medio del reconocimiento físico va en paralelo con una inseguridad en sus acciones, que les lleva a consultar todos cambios que realizan en su físico. No obstante, ha habido un cambio sustancial en el objetivo de estos cuidados, ya que son más mujeres las que se cuidan para gustarse a sí mismas que para agradarle al hombre. Las mujeres que desean mejorar su autoestima por medio de su imagen, se diferencian de aquellas que cultivan su cuerpo por salud, por lo que se podría considerar que existen dos modos de actuar: "Están las que se cuidan de cara a los demás y las que se cuidan para ellas mismas, es decir las que se cuidan sanamente y las que quieren dar sensación a los demás de que se cuidan” (GD2).

Los casos en los que se buscan una identificación con un modelo de mujer que no coincide con la realidad de las féminas, vienen motivados por el deseo de recibir la aprobación de su imagen, a pesar de que ésta no corresponda a su carácter o personalidad.

\subsubsection{Ser hombre o ser mujer y la generación}

En comparación con otras generaciones, consideran que anteriormente las mujeres tenían el matrimonio como meta a alcanzar. Reconocen el peso que la maternidad ha tenido, en tanto que implicaba una presentación pública basada en la atracción para lograr estos fines: "Antes creo que se preparaba a las mujeres para casarse y como ahora no tenemos esa presión... La mujer estaba preñada y cuidando de la casa, ¿no? Entonces sí que era la imagen importante, creo" (GD1). 
Las abuelas de estas jóvenes no le dan mucha importancia a su propio físico pero sí que se preocupan por el que presentan sus nietas. Reconocen que existían demandas sociales que les afectaban en las pautas de presentación externa, sobretodo la elección del vestuario. Señalan que anteriormente los cuidados iban dirigidos hacía el fin del matrimonio, por lo que aparecería un modo de ser funcionalista encaminado a estos fines. A pesar de que en las sociedades actuales hay una mayor conciencia de igualdad, todavía existe una especie de subordinación de la mujer al hombre en la que este tiene un mayor protagonismo y una menor demanda. Piensan que existe un estándar mínimo que hay que superar para llegar a ser lo mismo que un hombre. Señalan que el concepto de igualdad debería cambiarse por el de equivalencia, entendido como el valor por ser personas.

Esta igualdad la observan tintada de unos toques de hipocresía en los que aparecen diferentes constructores de esta realidad, como los medios de comunicación, que continúan manteniendo elementos diferenciadores. Opinan que existen mujeres machistas, influenciadas por la educación que han recibido desde pequeñas. Muchas mujeres critican a otras mujeres por la presión y el canon social que quieren alcanzar. "Criticamos a las mujeres de las revistas pero nos sentiríamos mejor si fuéramos realmente así" (GD1).

Pronostican que las demandas físicas se van a igualar entre sexos por el nuevo "ideal de hombre", el cual forma parte del mercado del cuidado corporal y consume productos que anteriormente iban dirigidos exclusivamente a las mujeres. Este prototipo masculino se presenta en la publicidad y en los medios de comunicación como atractivo a seguir.

\subsubsection{Publicidad: Creadora y cómplice del Discurso}

Existen diferentes formas de comunicar o publicitar el ideal de belleza mediante modelos. La televisión y el marketing le conceden mucha importancia al físico e incitan el consumo de ropa, maquillaje, dietas, estética, etc. A pesar de ser conscientes de todas estas influencias mediáticas, coinciden en que hay que establecer unos límites. Una 
alternativa para no caer en las presiones es tener una visión realista y evitar la competitividad: "No existen esas mujeres, las mujeres naturales no son como las de las revistas; yo pienso que es así, y que nos presionamos mucho entre nosotras mismas, entre las mujeres" (GD1).

Tanto las modas como la publicidad terminan por participar el uno del otro y viceversa. Señalan que existe un doble juego en el que la publicidad marca unos estereotipos y los medios de comunicación los mantienen. Opinan que se debe unir la belleza con el cerebro, sino es un absurdo alabar cuerpos sin tener en cuenta la capacidad mental. Imitar la publicidad es asimilar lo fácil, pero no deja de ser una libertad impuesta, puesto que opinan que "cada vez tenemos más libertad de elegir las cosas que nos imponen". Se trataría de un efecto oasis en la libertad de elección, en la que la consideración de que existe el criterio propio obvia el juego intrínseco del consumismo, sistema publicitario y medios de comunicación por el que esta manejado. Se elije entre los productos que el mercado válida, el individuo los acepta y pasa a ser un consumidor pasivo.

\subsubsection{Críticas ante la situación}

La excesiva valoración concedida al cuidado del cuerpo se debe a que en la actualidad prima el materialismo, superficialidad y consumismo. Hay un extremo peligroso que se observa en las modelos y en aquellas personas que siguen ese prototipo, que tiene que ver con enfermedades que surgen a raíz de la obsesión por tener un determinado peso. Las nuevas demandas de belleza masculina polarizan los modos estéticos y están creando un nuevo mercado del físico, el cual consideran que es un error y un retroceso cultural. El modelo económico social actual no facilita los cambios en los imaginarios de belleza existentes, ya que predomina una dependencia consumista que mantiene al mercado productivo, mediante la venta de productos para el cuidado, prendas de ropa, operaciones de cirugía estética, y actividades complementarias. La publicidad se 
mueve por el fin último de una adquisición económica acelerada, sin tener en cuenta el consecuente resultado en los hábitos de sus consumidores.

\section{Conclusiones}

El entendimiento de los significados intrínsecos de la realidad se realiza por medio del conjunto de los niveles de introspección insertos en los elementos instituidos que se proyectan sobre lo instituyente. Presentamos los niveles estudiados bajo tres reflexividades o introspecciones diferenciadas. El primer nivel es en el que se proyecta la conciencia de la realidad, la cual se muestra bajo los referidos al espacio público y a la publicidad. Este nivel posee contenidos y percepciones de lo instituido y de lo instituyente. En el segundo nivel, la proyección se centra en la observación de la realidad, la cual se muestra bajo la palabra subjetiva de los discursos juveniles, los cuales surgen del conocimiento que poseen de observar los diferentes escenarios y contextos. La tercera reflexión se refiere a la construcción de la realidad, por la que se crea la gnosis entre el ser o el deber ser del ideal femenino.

Cuadro 1. Relaciones entre lo instituido y lo instituyente en los niveles de gnosis estudiadas 


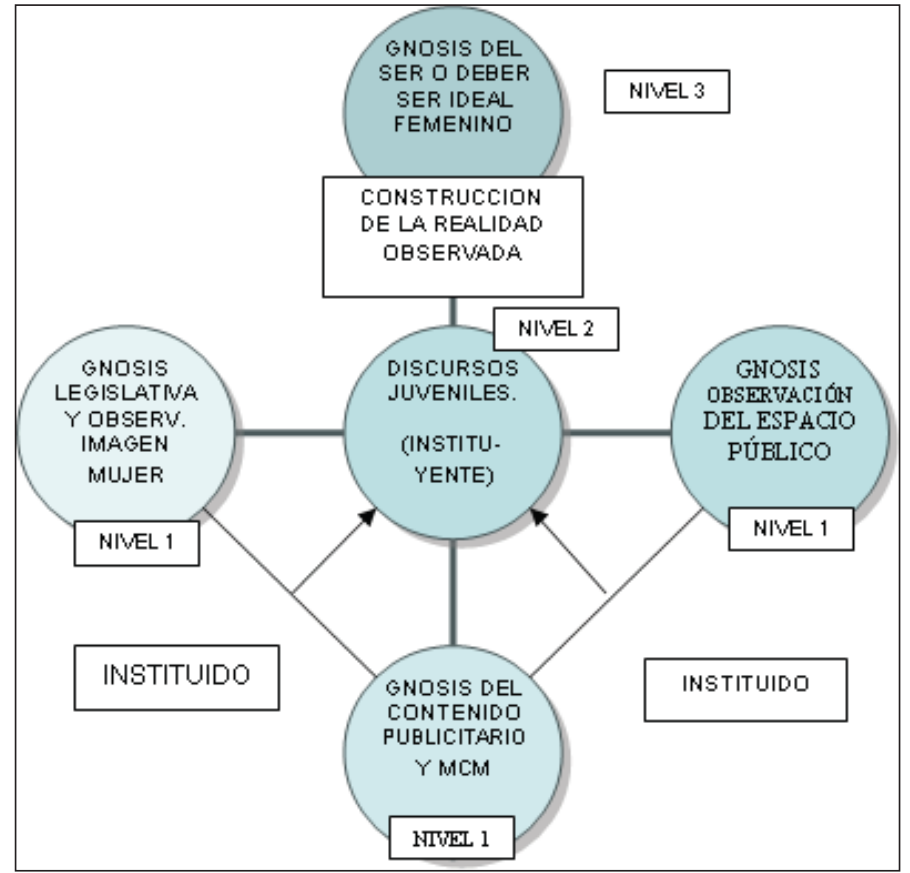

Fuente: Elaboración Propia

Tanto las fuerzas instituidas como las instituyentes terminan por participar en la construcción de los imaginarios e ideales, por lo que ambas aportan influencias en la construcción de la realidad y en las diferentes acciones de la vida cotidiana. En el nivel medio de los discursos juveniles, existe una mayor conciencia de que mediáticamente se está creando una influencia del deber ser ideal, la cual afecta tanto a hombres como a mujeres, en la reconfiguración de su imagen y presentación física. Esta percepción se refleja en las denuncias del informe del año 2008 del Observatorio de la Imagen de las Mujeres, en el que la tendencia de quejas de medios no publicitarios comienza a igualarse, a diferencia de años posteriores en los que las denuncias no publicitarias eran mínimas. En el último año se ha producido un descenso de quejas al Observatorio, lo cual puede indicar que se están modificando los modos prototípicos de mostrar a las mujeres en los medios de comunicación. No obstante, los discursos juveniles obvian el efecto legislativo en la creación o mantenimiento de ideales, y desconocen la existencia de los recursos de denuncia a la publicidad estereotipada. 
Para alcanzar el éxito en el cambio de las concepciones de belleza, hay que modificar las modas y el sistema de consumo occidental. Es necesario realizar un pacto social que sirva para adquirir una conciencia colectiva, en la que lo primordial sea el ser personal y no el deber ser externo. Para alcanzar estas metas, apuestan por una educación participativa, horizontal, colaborativa y colectiva, que sea desde la infancia y que garantice un éxito a futuro en los contenidos internos del pacto social. Cabría incluir la posibilidad de crear un marco legislativo que diera cabida a las opiniones colectivas de denuncia y de propuestas.

Por el peso de las influencias externas y de las gnosis instituidas, proponen nuevos cambios políticos, económicos y sociales para reconceptualizar los imaginarios ideales colectivos. La dificultad radica en la inmovilidad del sistema legislativo y en el desconocimiento de las capacidades de los recursos normativos, ya que no se asocia la construcción de un ideal de belleza como un valor intrínseco en las diferentes aportaciones legales. La posición ideológica del trasfondo legislativo es la de una posición paternalista en relación a la mujer, la cual pasa a ser objeto principal a defender frente a la publicidad ilícita, junto a la infancia y a la juventud. Uno de los primeros pasos a acometer es dotar a los ciudadanos de la posición de sujetos activos, con capacidad en la toma de decisiones y en la reformulación de las pautas culturalmente aprendidas.

Si el sistema social es un sistema abierto a buscar nuevos fines, es indispensable seguir a Ibáñez (1994: 29) y reproducir el sistema cambiando. Al ascender de nivel estos cambios son más difíciles e imposibles, pero también más necesarios. Plantear la investigación de género como un tema demasiado tratado por la ciencia social no deja de ser una realidad, pero obviar la existencia de que todavía quedan aspectos que tratar, y cambios necesarios que proponer, terminaría por ser una gran equivocación. Son agentes de cambio de esta investigación las normas legislativas, la publicidad y los jóvenes.

En relación a las normas, Pitch (2003: 233) se pregunta acerca de cómo cambian las normas, y las relaciones existentes entre cambio social y cambio normativo. Incorpora la cuestión de quiénes son los actores del cambio, quiénes serán estos sujetos, y qué motivaciones y objetivos les moverán en pro de un cambio legislativo en el 
comportamiento ciudadano. Lo importante es contrastar si realmente las manifestaciones por un cambio han tenido algún impacto normativo y de reestructuración de los ideales y de la transmisión de los mismos.

La publicidad ostenta la posición de creadora de la imagen de las mujeres en la muestra de unos estereotipos y unas actitudes. De Miguel et al. (2004: 81) aluden a la necesidad de sobreponer los valores del ser para recuperar la dignidad e ilusión en la construcción de un modelo más fuerte y con mayor capacidad de resolución de los problemas cotidianos.

A partir de este punto se abren dos posibles líneas análisis. En primer término, el estudio de la diversidad de prácticas de cuidado según la sociología de lo cotidiano. En segundo término, la posibilidad de crear un diálogo entre el mundo legislativo y el instituyente, mediante las inquietudes del conjunto poblacional.

\section{Referencias bibliográficas}

Acosta Estévez, José B. 1990. Perfiles de la Ley General de Publicidad. Barcelona: PPU. Amorós, Celia. 2000. Feminismo y filosofía. Madrid: Síntesis.

Bergua Amores, José Ángel. 2007. Lo social instituyente. Materiales para una sociología no clásica. Zaragoza: Prensas Universitarias de Zaragoza. Colección Ciencias Sociales.

Buttler, Judith. 2002. Cuerpos que importan. Sobre los limites materiales y discursivos del sexo. Buenos Aires: Paidós.

Código de Publicidad. 2005. Madrid: Marcial Pons.

Cottet, Pablo. 2006. "Diseños y estrategias de la investigación social: El caso de la ISCUAL". Metodologías de Investigación Social. Introducción a los oficios. Ed. Manuel Canales Cerón. Santiago de Chile: LOM.

De Beauvoir, Simone. 1976. Le deuxiéme Sexe II. Mónaco: Gahimard. 
Decreto 3339/1968, de 26 de diciembre, que dicta normas sobre registro, elaboración, publicidad y venta de cosméticos. Boletín Oficial del Estado núm. 24, de 28 de enero de 1969.

De Miguel, Clemente, coord. 2004. La Identidad de género en la Imagen Televisiva. Madrid: Instituto de la Mujer.

Despentes, Virginie. 2007. Teoría King Kong. España: Melusina.

García Selgas, Fernando. 1994. "Mujer y cultura. Un cuaderno de viaje”. Cuadernos de relaciones laborales, 4: 174-175.

Garfinkel, Harold. 2006. Estudios en etnometodología. Barcelona: Anthropos.

Goffman, Erving. 1991. Los momentos y sus hombres. Barcelona: Paidós.

Haraway, Donna. J. 1995. Ciencia, cyborgs y mujeres. La reinvención de la naturaleza. Madrid: Cátedra.

Ibáñez, Jesús. 1985. Del algoritmo al sujeto. Perspectivas de la investigación social. Madrid: Siglo XXI.

. 1986. Más allá de la sociología. El grupo de discusión: Técnica y crítica. Madrid: Siglo XXI.

. 1994. El regreso del sujeto. La investigación Social de segundo orden. Chile: Siglo XXI.

Informe Observatorio de la Imagen de las Mujeres. (2000 -2008). Instituto de la Mujer.

Lacan, Jacques. 1977. The Mirror Stage. Nueva York: Norton.

Legislación publicitaria. 1998. Madrid: Tecnos.

Ley General de Publicidad y legislación complementaria. 1989. Madrid: Civitas.

Ley 34/1998, de 11 de noviembre de 1988, general de publicidad. Boletín Oficial del Estado núm. 275, de 15 de noviembre de 1988.

Luhmann, Niklas. 2000. La realidad de los medios de comunicación de masas. Barcelona: Anthropos.

Pitch, Tamar. 2003. Un derecho para dos. La construcción jurídica de género, sexo y sexualidad. Madrid: Trotta.

Rodríguez Borges, Rodrigo Fidel y Domingo Fernández Agis. 2008. Comunicación mediática y espacio público. Santa Cruz de Tenerife: Universidad de La Laguna.

Roiz, Miguel. 2002. La sociedad persuasora. Control cultural y comunicación de masas. Barcelona: Paidós. 
Real Decreto 475/1995 de 5 de abril, por el que se modifica la reglamentación técnicosanitaria, aprobada por Real Decreto 349/1988, de 15 de abril. Boletín Oficial del Estado. núm. 86, de 10 de abril de 1991.

Real Decreto 1599/1997, de 17 de octubre, sobre productos cosméticos. Boletín Oficial del Estado. núm. 261, de 31 de octubre de 1997.

Santiso, Raquel. 2001. "Las mujeres en la publicidad: análisis, legislación y aportaciones para un cambio". Acciones e Investigaciones Sociales, 13: 46-60. 